in this way can scarcely long escape repudiation and overthrow. While scientific workers are of no two minds as to the necessity for whatever armaments we must have being efficiently produced and maintained, they would find a very considerable support for opposition to any system which demanded their efforts in the development of offensive, as opposed to defensive, weapons indefinitely. Moreover, the scientific worker in matters of national defence should require no further stimulus than his specific occupation if those ethical needs are satisfied. If, on the other hand, they are left unsatisfied, it is doubtful whether any system of armaments manufacture can supply a stimulus as effective.
The report of the Royal Commission accordingly will be something of a disappointment to those scientific workers who are concerned with the ethical aspects of their participation in the preparations for national defence. It gives no lead on certain of these questions of research and development which, apart from the ethical aspect, are equally to be encountered in other fields of industrial and scientific research. At least, however, it emphasizes once more that the task of constructing world peace involves not merely the abolition of war, but also the far-reaching and impartial study of all its many causes, and not least that of the contribution and organization of the armaments industry itself.

\title{
Genetics and Race
}

IN the classificatory systems of a number of sciences the term 'race' occurs. Its meaning differs somewhat from science to science, but in all it has two main connotations, one being community of descent, the other distinctness from other races. Years ago the term signified something rather definite, but as time has passed and knowledge has advanced, this has given place to something much more vague. In general biology, for example, 'race' has now been largely abandoned in favour of 'sub-species'-a term much more in harmony with the concept that it is used to portray.

So long as the definition of race in the usage of one science does not invade the territory of another, it is a matter of no great importance if there are as many definitions as there are sciences ; but if and when the term race as used by the physical anthropologists, for example, comes to have genetical implications, then it is reasonable for the geneticist to express the view that the anthropologists' definition must neither disregard nor offend genetic principles. This it does, for the anthropological use of the term dates from the time when it was believed that organic inheritance was of the blending variety, so that a mixed population would speedily approximate to a characteristic uniform type. This assumption has been shown to be incorrect by the establishment of the Mendelian basis of inheritance, and it is now known that constellations of characters necessarily become broken up and their ingredients shifted back and forth, combined and recombined, when, consequent upon the removal of isolation and inbreeding, crossing occurs. Furthermore, the assumption that man's evolution has taken the form of a separation into discreet isolated units is also incorrect, since migration and crossing have been operative for tens of thousands of years, so that, whereas the evolution of most animal types is divergent, that of man has been what may be called reticulate.

This was the reason for a joint meeting on September 11 of Sections H (Anthropology) and D (Zoology) of the British Association at Blackpool, at which the speakers were primarily concerning themselves with the question of whether or not the anthropologist's definition of race required modification in consequence of recent developments in genetics. But no one at this crowded meeting was unaware that the speakers were indirectly commenting upon the exploitation of the race concept by politicians who apparently are deliberately confusing linguistic terms such as 'Aryan', cultural terms such as 'germanic' and genetic terms like 'Nordic' by using them synonymously. It undoubtedly is the case that the term 'race' is now being used in a pseudo-scientific sense to further purely political interests, and this being so, it behoves all scientific workersanthropologists, ethnologists and the rest-to respond to the demand on the part of the general public for guidance concerning the quality of the pronouncements of those who claim scientific 
endorsement for their own peculiar attitudes toward such matters as territorial readjustment, immigration quota or the relative intellectual pre-eminence of certain national groups.

The impression left at the end of this meeting was that the anthropologist's definition of race has genetical implications, that it has been established that the rise of modern genetics has necessitated a thorough overhaul of the basic concepts of physical anthropology, that the techniques of genetics should now be added to those of the anthropologist, and that genetical analyses of human differences and the correlation between them should be undertaken, and that, as applied to mankind, it is now quite impossible to give a scientific definition to the term 'race' since this has connotations which do not apply in human species. Now that the politician has appropriated the term, it is time for the man of science to relinquish it.

\section{Sixty Years of Physical Science}

Recollections and Reflections

By Sir J. J. Thomson. Pp. viii $+451+10$ plates. (London : G. Bell and Sons, Ltd., 1936.) 18s. net.

IT is hard to believe that Sir Joseph Thomson 1 will enter the ranks of the octogenarians on December 18-he has given, and is giving, so much to the world that it may very well happen to him as to Voltaire, who awoke one morning to find the world celebrating his eightieth birthday, he himself having scarcely had leisure to realize that he had reached middle-age.

Sir Joseph has seen many cities and many men ; and, in the spirit of the Spanish proverb which says that "He who would bring back the wealth of the Indies must take that wealth with him", we should expect Sir Joseph's reflections on his voyagings in thought and in space to yield a rich harvest indeed.

Nor shall we be disappointed. The changes which he records are, in the total, almost incredible in their extent and variety. In that Palmerstonian world into which he was born, the University of Cambridge was still governed by those medieval statutes of the workings of which the late Dr. John Venn has left so vivid a picture. Memories of those days, when Hall was at 4 , when water, of doubtful origin, was carried from pumps, and smallpox patients went through the various stages of their disease in bedrooms opening on a common staircase, still lingered on in that yet far-off Cambridge of 1876 , when J. J. Thomson entered his name on the books of Trinity College. Sixty years have passed and the undergraduate of 1876 , now Master of Trinity, has kept every term since then, and has been in residence for some part of every long vacation. Nor, as he remarks, can he remember any day during the last sixty years when his work has been interrupted by bad health. A remarkable record, and one which has probably been surpassed only by old Dr. Routh
(1755-1854), the venerable President of Magdalen, who walked over Magdalen bridge, an undergraduate of fifteen years of age and thereafter left Oxford but once, on an abortive trip to France.

The Cambridge of 1876 was awakening to the importance of physical science. Maxwell had been appointed to the Cavendish chair in 1871 and the quadrant electrometer loomed large in the land. Maxwell himself was deeply immersed in the study of the Cavendish papers, and was enthusiastically repeating those remarkable experiments in which Cavendish had arrived at correct notions of the meaning and magnitude of electrical resistance by making of himself a human galvanometer, estimating current strength by the intensity of the shock he felt in his elbow when the current was discharged through his body. Distinguished visitors were called on, very much against their wills at times, to repeat the experiment, and Sir Joseph's recollections of the period range easily from topic to topic, now sketching Maxwell's work, now moving to a masterly account of Cavendish's meticulously accurate experiments and queer personality and again moved by a recollection of Cavendish's 'gar-do' methods, as the Scots phrase has it, making a neat comparison of Cavendish's and the late Lord Rayleigh's experimental technique, for each experimenter had the gift of seeing what was the vital point in the experiment, so that "though the apparatus as a whole might look untidy and haphazard, the parts that really mattered were all right. It was a 'rum 'un to look at, but a beggar to go'."

Sir Joseph's interests are catholic and his memories are ranging. Figure after figure comes to life, invoked by the power of a kindly memory and a genial pen, and we hear much of the giants of past days, and something of those who are still with us. The portraits of Butler, Thompson and Whewell, Sir Joseph's predecessors in the mastership of Trinity, are skilfully etched, and it 